\title{
Evaluation of virtual assessment
}

Pauline Joyce ( $\nabla$ pjoyce@rcsi.ie)

Royal College of Surgeons in Ireland

Dara Cassidy

Royal College of Surgeons in Ireland

Laura Kenna

Royal College of Surgeons in Ireland

\section{Research Article}

Keywords: Long case, OSCE, high stakes' exam, virtual platform, CIPP

Posted Date: December 20th, 2021

DOI: https://doi.org/10.21203/rs.3.rs-1128582/v1

License: (1) This work is licensed under a Creative Commons Attribution 4.0 International License. Read Full License 


\section{Abstract}

\section{Background}

The study emerged from the necessity to reschedule an in-person long case examination to an online platform for Physician Associate students' final clinical examination. The group had already experienced a delay in taking this clinical examination due to missing clinical hours, during Covid-19 restrictions. The aim of this study was to evaluate the experiences of students and examiners for a high stakes' clinical examination online. Research suggests that the long case is the only clinical examination that promotes holistic assessment. However, a disconnect between the patient's presence and the student in the virtual environment was a key finding in this study.

\section{Methods}

This was an evaluation research study, using the Context, Input, Process, Product (CIPP) model, which provided a framework to establish the effectiveness and/or success of an online format for a high stakes' clinical examination. All students and examiners were invited to take part in virtual interviews.

\section{Results}

Results suggest that both students $(n=5)$ and examiners $(n=7)$ agree that, while the stress of a face-to-face examination was lessened for the student, this was balanced by a new stressor of potential internet problems. All agreed that a virtual setting for a high stakes assessment is not transferable, with both groups citing the lack of opportunities to 'read the patient' and 'showcase their physical exam skills' as challenging.

\section{Conclusions}

Our study suggests that, in the context of balancing the risks of the pandemic with graduating healthcare professionals, the online format was a success. The benefits cited included the preparation of students for real life situations in a clinical setting, with a healthcare system now more reliant on virtual consultations, and the capacity to offer increased opportunities for formative assessment of consultation and clinical reasoning skills. However, recommendations suggest that the long case could be planned so that student and patient are in the same setting to perform a ten-minute physical exam, confirming the finding that questions on 'how to' examine a patient are no substitute for 'doing'.

\section{Background (Context \& Purpose)}

From the initial national lockdown in Ireland Physician Associate (PA) students wondered how much of an impact the interruption to their workplace learning would have on their completion of the programme and ultimately qualification as a PA. When students finally resumed clinical placements, they were further challenged by the constraints of physical distancing, which impacted on examining patients close-up, e.g., their mouths, eyes etc. In some instances, they were not permitted to examine patients at all due to risk of Covid-19. Literature suggests that these constraints have heightened the level of anxiety of students that can threaten their wellness (1).

The context of the assessment evaluated here emerged from the necessity to move from a planned in-person examination of clinical skills with patients to an online examination. Healthcare settings have adapted teaching during Covid-19, such as beside rounds to virtual beside rounds (2), face-to-face lectures with webinars, and some transferring to a problem-based learning approach online (3). The rise in Covid-19 numbers after the Christmas 2020 period made face-to-face clinical examinations high-risk as the Alpha variant of the virus was present in the community. At the same time the student group had already experienced a delay in taking their final examinations (planned for November 2020) due to missing clinical hours, which had to be made up to satisfy the curriculum. Some medical schools brought final examinations forward to increase numbers of qualified healthcare staff available to work during the pandemic (4). However, the PA programme is a two-calendar year accelerated programme and all clinical hours scheduled are required to graduate a safe practitioner. The need to balance the risks and benefits (5) during this fraught time was uppermost in everyone's minds. Medical school administrators faced the challenge of protecting learners while also minimising interference with their medical education (6).

Even with a small number of students $(n=10)$ for clinical examinations, there was a potential of 25 people being in close contact for up to two hours. An observed structured clinical examination (OSCE) examination was already scheduled for the previous day of the long case examination and this was judged safe to proceed, due to the short duration of the OSCE stations (8 minutes per station) with simulated patients. Safety protocols and physical distancing were followed, as per other institutions, to lessen the risk of Covid-19 spread (7, 8). The clinical examination skills assessed during the OSCE were deemed a sign-off on the student's physical examination skills. Therefore, the physical examination component of the long case was altered to focus on clinical reasoning skills of the student (9). The choice of physical examination deemed appropriate to carry out for the patient scenario in question and describing the technique of the examination was the focus of this part of the long case (10). While the limitations of the traditional face-to-face long case examination, such as examiner and patient variability, have been reported elsewhere (11),(12), an opportunity to test the examination using a standardised patient with two examiners, presented itself. This time sensitive decision, for the safety and wellbeing of all stakeholders (13) was approved by the external examiner of the programme. The students had 
previously carried out a face-to-face long case examination during the previous semester and were asked to draw of this experience to compare to the online examination experience.

The purpose of our study was to evaluate the experiences of a virtual assessment of PA students in their final clinical examination, from the perspectives of the examiners and the students. The study takes advantage of an innovative opportunity to evaluate an online assessment with a view to lessons learned, should this assessment process be used in the future. As the PA students, who are now graduates, navigate a healthcare system, which is more reliant on virtual consultations with patients, it can be argued that the use of virtual platforms, such as Blackboard Collaborate, prepares the student for real life situations in a clinical setting. The platform has been evaluated as a time efficient, easy to use technology (14). Despite technical glitches, i.e., occasional time delay and audio echo, it was viewed as an efficient virtual medium. Given the uncertainty regarding duration of the impact of COVID-19 on clinical practice, PA graduates have found themselves using telehealth, even if temporarily, to limit interactions and ensure patient safety (15).

\section{Method}

This is an evaluation research study, using the Context, Input, Process, Product (CIPP) model (16) [Figure 1], which provides a framework to establish the effectiveness and/or success of an online format for a high stakes' clinical examination. The CIPP model particularly focuses on the inputs and process for the assessment evaluated, presented within the context of the pandemic. Prior to the examination, students received a number of practice sessions, using the Blackboard Collaborate platform. Some examiners had been using the platform since the pandemic restrictions were implemented while some of those examiners outside the organisation had already examined communication skills using this platform. Those who were not familiar with the platform received training. To satisfy the input part of the CIPP model, literature was reviewed to check the evidence on validity of online examinations. The product, which relates, in this case, to the results of the examination were not the focus of the study but merely an observation in the presentation of findings, as compared to a face-to-face long case examination. The core values of the programme are those of the university in which the programme is run, i.e., Respect, Collegiality, Scholarship and Innovation. All methods were carried out in accordance with relevant guidelines and regulations under ethics approval and consent to participate. Written informed consent was obtained from all subjects.

Within the framework of the CIPP model, this was a retrospective study using a descriptive qualitative case study design, with a focus on the experiences of participants as per Yin's approach (17). All 10 healthcare professionals who were involved in examining final long case examinations (two per student) and the entire group of PA students $(n=10)$ who took these exams were invited to participate. The gatekeeper (LK), via university email addresses, recruited them. The healthcare professional examiners comprised five consultant doctors and five PAs, who were matched in pairs to examine one student each during a 40 minutes' examination online. The normal breakdown of this examination is fifteen minutes for a focused patient history, five minutes to report back to examiners, ten minutes of physical examination of the patient and ten minutes of questions and discussion with examiners. The students, who were undertaking their final long case examination, had completed their programme, when invited to take part in this research. There was a $60 \%$ response rate.

Data was collected via virtual one-to-one interviews, using MS Teams, and lasted approximately 30 minutes each. They were carried out by one researcher (DC), who was not one of the faculty on the programme, but has a background in digital learning. Interviews were recorded, transcribed, and analysed using thematic analysis. Once transcribed and pseudonymised (LK), both researchers (DC, PJ) used Braun \& Clark's six step process (18) to guide the analysis, separately and then met to share their findings.

\section{Results}

Having two researchers involved in the data analysis allowed discussions to take place around final themes, how data supported the themes, and if themes overlapped. Five students (S1-5) and seven examiners (E1-7) took part in the interviews. While themes overlapped between students and examiners these were experienced from different perspectives. The interview prompts also explored their recommendations for using a virtual assessment format in the future. The data is presented under three final themes: 1. Stress, 2. Holism and 3. Transferability, with direct quotes from students and examiners as relevant.

\section{Stress}

This theme represents participants' references to feelings of uncertainty, feeling stressed or calm, and reading the situation as daunting. For most students, there was a balance of being calmer in their own home environment before the exam but worrying about how the physical examination part of the assessment would translate online:

it was very calming being in your own surroundings...got a coffee with my mum when it was over...you are more relaxed...sometimes the adrenaline of an exam helps you along... (S1) 
However, this student also felt that '...it was a bit daunting to try a new form of examination for our final exam... (S1). Trying to figure out the transferability of the physical examination of the patient online was a challenge for all students e.g.

....another level of stress...so worried about how we were going to talk through the physical exam... (S3)

Because of Covid-19, the examination format was changed to online within two weeks of the date set, following approval from examiners. This was then communicated to students, so that preparation for the virtual assessment created uncertainty for the group as verbalised in this quote:

... what was challenging was there were a lot of unknowns up till the last point of how our exams would happen...I was not certain if I was saying or doing the right things... (S3)

On the other hand, some examiners expected there to be more stress for the student in a face-to-face exam, for example:

...it (long case) seems to generate a tremendous amount of anxiety, and it stems from this power differential. When you are in the room physically with two examiners and a student...it seems to generate a tremendous amount of anxiety (E7)

Yet, as an examiner, this person admitted'... I was nervous...I did not want to mess it up... It is different than just going to sit in a room and examine the student' (E7)

For most examiners the stress during the virtual exam was related to internet connectivity concerns, with a feeling that there is '... always some technical difficulty...some technical glitches' (E5). However, one examiner regarded it as '...an excellent platform...We were lucky it all went so smoothly (E6).

Transferring such a high stakes clinical examination online did bring its challenges such as the holistic assessment of the patient, discussed in the next theme.

\section{Holism}

This theme incorporates the perception that a physical examination makes for a more holistic assessment. The belief that the student needs to be able to read the patient and the view that there is a disconnect in the virtual experience as the patient acts as a trigger for the examination process.

One student described this as:

I find (the in-person examination) a better situation for me in terms of getting the information I want from the patient and being able to gauge their reactions and looking for different cues from them. (S4)

However, another student highlighted the disconnect between the patient's presence face-to-face and the virtual environment, stating that it was not of any benefit as a graduating PA:

It was more comfortable for me, but I do not feel like it was beneficial for me as a clinician. I do not get anything from this. I mean, I can talk to you online, ...you cannot see that my body language is completely different than for me to walk into a patient and do this. (S5)

Likewise, from the examiners' perspectives:

...you will never fully replace a long case...the reading of things like body language...prefer real live patients...the relational stuff...communicating... (E3)

Including physical exam makes for more holistic assessment...a better rapport with people if it is in real life...you can kind of sense things more and there is a better flow...I always think in person is nicer (E1)

A number of examiners agreed that the face-to-face examination gives a 'more holistic experience' (E2; E3; E5; E6). Students concurred with this sentiment, overall, preferring a face-to-face exam. The following is typical of how students verbalised this sentiment:

...the non-verbal cues that you would get from a history from a patient...not as evident because you were just looking at a computer (S1).

I do prefer the patient interaction in person and being able to speak directly to the patient and having that closer interaction (S2).

On the other hand, students acknowledged that, while virtual clinics have a place in healthcare, they do not exclude the need for in-person appointments, as the following sample quote suggests

...eventually some patients do need to be seen in person...virtual clinics are the next way forward. During Covid, it was a safer thing not only for consultants and us, but also for the patient...safety comes first and it is just the safer way for everyone involved. (S1) 
For an examiner the issue of spontaneity was an issue:

It is hard to be spontaneous...you have to wait until they finish talking so you can then interject something. (E7)

While another examiner felt that 'you could give them a bit more direction if you were beside them...encourage them'. (E4)

These findings lead into the question of whether or not virtual clinical examinations are transferable or not, which is the final theme.

\section{Transferability}

While the long case examination was planned in such a way that all elements of the assessment, except for the student performing a physical examination of the patient, were followed as for a face-to-face examination with timing unchanged, the examiners agreed that the in-person format was not transferable to the virtual format. Responses to the prompt about using this assessment in the future included:

...it is not mimicking a real situation, or an inpatient scenario...not a true face to face interaction (E2).

...it is not the same being able to see both the student, your co examiner and the patient participant...I can't read body language ... read the facial expression (E3).

While not recommending an online long case examination as a final assessment, this examiner acknowledged the convenience of it, and being able to examine someone if you worked in a different setting.

...it, it is handy to turn on your phone and examine someone if you are working somewhere else. So, it gives you more opportunity to have more of a range of examiners, for students as well. And it is good...if you have more of these exams opposed to less in-person ones, then you are getting more experience and training. (E1)

One student suggested that you could score higher on a virtual examination but would still not recommend it for future assessments

I feel the physical ones are more real, they are setting you up for the future and if you mess up on something, it can be corrected straight away. With long cases online, you could be doing so many things wrong and you may never get it correct. So, you are going to keep doing it. With an online long case, you are not examining physical skills at all. But it is easy for the students because you can score higher. (S5)

Likewise, this student did not see it as a substitute for the final long case examination but more as a supplemental type of examination, where students could practice being assessed.

I would recommend it as an addition, a way for students to be assessed more frequently by examiners, when in person things cannot be organised or there's not capacity for it or there is not the space, I think it does give you a chance to run through what a long case is meant to be. You know, you can take a history from your patients. Like I have mentioned, the physical exam part is really challenging. But the questions at the end, that is the same that you would get, even if you were in person. So, there is a space for it, but more like a supplemental type of examination. But, I would not think it should be the sole method of examination for long cases. (S3)

While beneficial for history taking and having a place for practice sessions S2 believes that an in-person examination is better:

You are better off to do physical exams in terms of OSCEs and long case in person, it makes sense. The examiner cannot see your technique online. They can't see that you know, where you are listening to, with your stethoscope. Yes, it is important anatomically to know what people are doing. (S2)

In summary, it seems that, in the context of the pandemic and the challenges which were faced by students and examiners, the virtual assessment met the needs at that time. In relation to the Product of the CIPP model, results for these students were comparable with results from their inperson long case examination in the previous semester.

\section{Discussion}

An evaluation of a long case examination using a virtual platform has clearly been challenging for examiners and students, albeit in different ways. Covid-19 brought a scenario like no other, meaning that the students in our study had reduced time in the clinical setting prior to exams. They could have felt less prepared for areas of practice, that are based on experiential learning, a finding that has been found previously (19). Some students felt more relaxed in their own environment, perceiving the virtual environment to be less daunting and stressful than in-person settings. The virtual assessments were also viewed to be time efficient, enabling clinicians to participate remotely from clinical sites (20).

Furthermore, the use of virtual platforms offers students an opportunity to develop their telemedicine consultation skills in advance of undertaking online consultations in real practice (21). Some primary care providers have reported using telemedicine more than five times a day during Covid- 
19 (22). In a context where COVID disruption is ongoing and there is increasing chance of similar pandemics in the future (23), virtual approaches can help build resilience into higher education (24).

According to Tijani et al (12) the examiner variability of the long case is well known so that the OSCE is included for clinical examinations in medicine to counteract such potential variability. Following their study, and comparing both forms of assessment, they recommend using both rather than replacing the long case with the OSCE, as the marks awarded for the long case do not reflect the global ability of the students. However, Tey's findings (25) suggest that the long case is the only clinical assessment that promotes holistic assessment, playing an important role in fostering clinical skills and encouraging students to spend time with patients. During the interviews, some examiners suggested that this was the only examination which tested holistic assessment. A number of students in Tey's study believed the long case to be an authentic representation of medical practice. This belief concurs with findings in our study where students believed that this was an opportunity to showcase all their skills. Equally, examiners believed that it mirrors what doctors do in their everyday work (25).

While acknowledging the long case as reaching the pinnacle of the programme assessment in Tey's study, students in our study believed that the virtual assessment version did not allow them to read the patient. They believed that they missed out on these in-person cues. It is well known that subtle shifts in voice can get lost in the digital noise and lack of direct eye contact, hidden body language or technical hiccups such as lag, can hinder the natural flow of conversation (26) Transferring their ability to talk through physical examination skills created another layer of stress for the students in our study as did the challenges of internet connectivity for both students and examiners, challenges found by others too (27) (28).

Leaving aside its challenges with reproducibility, the greatest strength of the long case has been cited as its evaluation of the student's performance with a real patient, presenting them with a realistic clinical challenge (29). The patients in this evaluation were simulated patients, who believe that they have an important role in healthcare education and that their unique insights play an important beneficial role in student learning (30). It is well accepted that a combination of clinical assessments such as the OSCE and long case is recommended for final medical examinations (11). Virtual simulations and clinical assessments have never served as substitutes for direct patient care (31). However, as was the case for our study, the physical examination part of the long case was verbalised, rather than performed, with an emphasis on the student providing clinical reasoning for the type of exam performed with an emphasis on verbalising technique. Clinical reasoning is seen as very important for physician associates (32) suggesting that it can contribute to reducing diagnostic errors (9). Similar to our findings, Hannon's study (10) found that students believed that narrating the physical examination caused the flow of the patient interaction to be awkward, and, more than half of their sample felt it was not as good as the in-person exam.

Overall, virtual examinations will only be continued if there are advantages to the student and examiner. There are many practical caveats to consider to decrease variations in experiences. Pettit summarise these as variations in home environments, which can affect internet issues such as WIFI and bandwidth, while busy households causing noise and potential interruptions are also real considerations (33).

\section{Conclusion}

Consensus was reached by students and examiners on the suitability of this type of online assessment for high stakes examinations beyond Covid-19. Clearly, a virtual assessment for clinical diagnosis and skills is not recommended for a final examination such as the long case. However, in the context of Covid-19 and the necessity to graduate medical professionals, such as physician associates, it was seen as achieving this goal. This group of students, rather than finishing earlier, finished later than scheduled as they needed to meet the curriculum hours for module credits. Graduating from an accelerated degree programme, patient safety was utmost in the minds of academics and examiners, so that virtual clinical examinations met the needs of the programme at this unprecedented time. Moreover, in a context where COVID disruption is ongoing and there is increasing chance of similar pandemics in the future, it is wise to build resilience into teaching and assessment strategies by working to optimise the use of virtual approaches to ensure that they are used appropriately to bring value where they can. The increased use of tele consultations means that consideration should be given to their incorporation into the PA curricula and in this case a virtual assessment would be wholly appropriate.

Finally, it was identified that virtual platforms may offer additional formative opportunities for rehearsal of clinical reasoning, history taking and communication skills, through their enhanced accessibility for busy clinician examiners. The CIPP model was a useful framework for this study as it focused on the importance of context and inputs before planning data collection. Reflecting on the pandemic, there have been many innovations which can be evaluated using such a model, so that we learn for future extraordinary teaching, learning and assessment challenges.

\section{Declarations}

\section{Ethics approval and consent to participate}

This study received ethical approval from RCSI Research Ethics Committee (ID No.: 212552115). All methods were carried out in accordance with relevant guidelines and regulations, under Ethics approval and consent to participate. Written informed consent was obtained, from all subjects. 


\section{Consent for publication}

Participants and authors have consented to publication of this manuscript.

\section{Availability of data and materials}

Data will be kept on a password-protected computer until the study is published. The datasets generated and/or analysed during the current study are not publicly available due to the possible recognition of individuals in the small sample, but are available from the corresponding author on request.

\section{Competing interests}

There are no completing interests to declare.

\section{Funding}

This study has not been funded.

\section{Authors' contributions}

DC collected the data. LK was the gatekeeper, transcribed and pseudonymised the data.

\section{Acknowledgements}

We acknowledge the contributions of all students and examiners who took part in the study.

\section{Authors' information}

Pauline Joyce is Director of Quality and Clinical Engagement of the MSc Physician Associate Studies; Dara Cassidy is Head of Online Education; Laura Kenna is Programme Coordinator of the MSc Physician Associate Studies.

\section{References}

1. Hall AK, Nousiainen MT, Campisi P, Dagnone JD, Frank JR, Kroeker KI, et al. Training disrupted: Practical tips for supporting competencybased medical education during the COVID-19 pandemic. Med Teach. 2020 Jul 2;42(7):756-61.

2. Hofmann H, Harding C, Youm J, Wiechmann W. Virtual bedside teaching rounds with patients with COVID-19. Med Educ. 2020 Oct;54(10):959-60.

3. Foo C, Cheung B, Chu K. A comparative study regarding distance learning and the conventional face-to-face approach conducted problembased learning tutorial during the COVID-19 pandemic. BMC Med Educ. 2021 Dec;21(1):141.

4. Lapolla P, Mingoli A. COVID-19 changes medical education in Italy: will other countries follow? Postgrad Med J. 2020 Jul;96(1137):375-6.

5. Barach P, Ahmed R, Nadel ES, Hafferty F, Philibert I. COVID-19 and Medical Education: A Four-Part Model to Assess Risks, Benefits, and Institutional Obligations During a Global Pandemic. Mayo Clin Proc. 2021 Jan;96(1):20-8.

6. Southworth E, Gleason SH. COVID 19: A Cause for Pause in Undergraduate Medical Education and Catalyst for Innovation. HEC Forum [Internet]. 2021 Jan 22 [cited 2021 Feb 17]; Available from: http://link.springer.com/10.1007/s10730-020-09433-5

7. Boursicot K, Kemp S, Ong TH, Wijaya L, Goh SH, Freeman K, et al. Conducting a high-stakes OSCE in a COVID-19 environment. MedEdPublish [Internet]. 2020 [cited 2021 Feb 17];9(1). Available from: https://www.mededpublish.org/manuscripts/2939

8. Samarasekera DD, Goh DLM, Yeo SP, Ngiam NSP, Aw MM, Lim MM, et al. Response and Lessons Learnt Managing the COVID-19 Crisis by School of Medicine, National University of Singapore. MedEdPublish [Internet]. 2020 May 6 [cited 2021 Jun 15];9. Available from: https://www.mededpublish.org/manuscripts/3034

9. Plackett R, Kassianos AP, Kambouri M, Kay N, Mylan S, Hopwood J, et al. Online patient simulation training to improve clinical reasoning: a feasibility randomised controlled trial. BMC Med Educ. 2020 Dec;20(1):245. 
10. Hannon P, Lappe K, Griffin C, Roussel D, Colbert-Getz J. An objective structured clinical examination: From examination room to Zoom breakout room. Med Educ. 2020 Sep;54(9):861-861.

11. Kamarudin MA, Mohamad N, Siraj MNABHH, Yaman MN. The Relationship between Modified Long Case and Objective Structured Clinical Examination (Osce) in Final Professional Examination 2011 Held in UKM Medical Centre. Procedia - Soc Behav Sci. 2012 Oct;60:241-8.

12. Tijani K, Giwa S, Abiola A, Adesanya A, Nwawolo C, Hassan J. A COMPARISON OF THE OBJECTIVE STRUCTURED CLINICAL EXAMINATION AND THE TRADITIONAL ORAL CLINICAL EXAMINATION IN A NIGERIAN UNIVERSITY. J West Afr Coll Surg. 2017;7(3):59-72.

13. Ashokka B, Ong SY, Tay KH, Loh NHW, Gee CF, Samarasekera DD. Coordinated responses of academic medical centres to pandemics: Sustaining medical education during COVID-19. Med Teach. 2020 Jul 2;42(7):762-71.

14. Hart T, Bird D, Farmer R. Using blackboard collaborate, a digital web conference tool, to support nursing students placement learning: A pilot study exploring its impact. Nurse Educ Pract. 2019 Jul;38:72-8.

15. Grenda TR, Whang S, Evans NR. Transitioning a Surgery Practice to Telehealth During COVID-19. Ann Surg. 2020 Aug;272(2):e168-9.

16. Kellaghan T, Stufflebeam DL. International Handbook of Educational Evaluation: Part One: Perspectives / Part Two: Practice. Springer Science \& Business Media; 2012. $1050 \mathrm{p}$.

17. Yin RK (2003) Case study research: Design and methods 3rd Edition. Sage Publications, London. - Google Search [Internet]. [cited 2021 Jun 15]. Available from: https://www.google.ie/search?

tbm=bks\&hl=en\&q=Yin+RK+\%282003\%29+Case+study+research\%3A+Design+and+methods+3rd+Edition.+Sage+Publications\%2C+London.+

18. Braun V, Clarke V. Using thematic analysis in psychology. Qual Res Psychol. 2006 Jan 1;3(2):77-101.

19. Illing JC, Morrow GM, Rothwell nee Kergon CR, Burford BC, Baldauf BK, Davies CL, et al. Perceptions of UK medical graduates' preparedness for practice: A multi-centre qualitative study reflecting the importance of learning on the job. BMC Med Educ. 2013 Feb 28;13(1):34.

20. Dara Cassidy, Catherine Bruen, Dr Martina Crehan, Gareth Edwards, Jenny Moffett, Helen Kelly, Professor, Jan Illing, Dr Andrea Doyle, Dr Maikki Cullen, Dr Gozie, Offiah, Professor Arnold Hill. Cassidy D et al Experiential learning: lessons learned from the Covid-19 pandemic [Internet]. Next Steps for Teaching and Learning. [cited 2021 Nov 11]. Available from: https://www.teachingandlearning.ie/wpcontent/uploads/RCSI.pdf

21. lancu AM, Kemp MT, Alam HB. Unmuting Medical Students' Education: Utilizing Telemedicine During the COVID-19 Pandemic and Beyond. J Med Internet Res. 2020 Jul 20;22(7):e19667.

22. Saiyed S, Nguyen A, Singh R. Physician Perspective and Key Satisfaction Indicators with Rapid Telehealth Adoption During the Coronavirus Disease 2019 Pandemic. Telemed E-Health. 2021 Nov 1;27(11):1225-34.

23. Marani M, Katul GG, Pan WK, Parolari AJ. Intensity and frequency of extreme novel epidemics. Proc Natl Acad Sci. 2021 Aug 31;118(35):e2105482118.

24. Weller M. DIGITAL RESILIENCE IN HIGHER EDUCATION. 2013;16(1):15.

25. Tey C, Chiavaroli N, Ryan A. Perceived educational impact of the medical student long case: a qualitative study. BMC Med Educ. 2020 Dec;20(1):257.

26. Venter E. Challenges for meaningful interpersonal communication in a digital era. HTS Teol Stud Theol Stud [Internet]. 2019 Apr 29 [cited 2021 Nov 15];75(1). Available from: https://hts.org.za/index.php/hts/article/view/5339

27. Tuah NAA. Is Online Assessment in Higher Education Institutions during COVID-19 Pandemic Reliable? Siriraj Med J. 2020 Dec 20;73(1):61-8.

28. Darnton R, Lopez T, Anil M, Ferdinand J, Jenkins M. Medical students consulting from home: A qualitative evaluation of a tool for maintaining student exposure to patients during lockdown. Med Teach. 2021 Feb 1;43(2):160-7.

29. Norcini JJ. The death of the long case? BMJ. 2002 Feb 16;324(7334):408-9.

30. Sullivan C, Condron CM, O'Connor L, Pawlikowska T, Murray JM. Their OSCE, not your Oscar: Simulated Patients' Perspectives. Clin Teach [Internet]. [cited 2021 Sep 8];n/a(n/a). Available from: https://onlinelibrary.wiley.com/doi/abs/10.1111/tct.13400

31. Hilburg R, Patel N, Ambruso S, Biewald MA, Farouk SS. Medical Education During the Coronavirus Disease-2019 Pandemic: Learning From a Distance. Adv Chronic Kidney Dis. 2020 Sep;27(5):412-7.

32. Gray J, Darling-Pomranz C, Jackson B. Developing Clinical Reasoning in a Physician Assistant Curriculum: The University of Sheffield approach. J Physician Assist Educ. 2021 Sep;32(3):159-63.

33. Pettit M, Shukla S, Zhang J, Sunil Kumar KH, Khanduja V. Virtual exams: has COVID-19 provided the impetus to change assessment methods in medicine? Bone Jt Open. 2021 Feb 1;2(2):111-8.

\section{Figures}




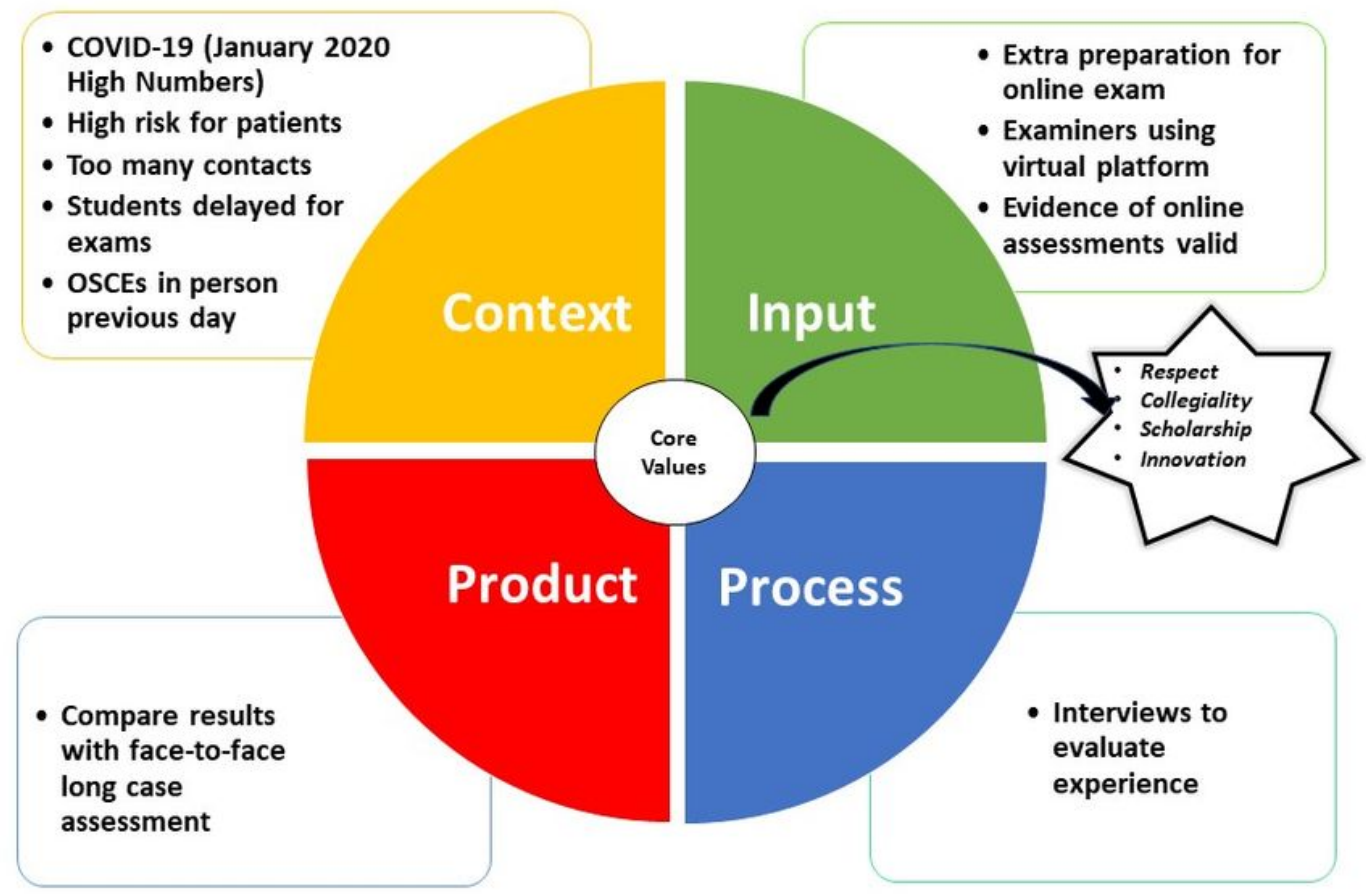

Figure 1

CIPP Model 